\title{
DECREASED IN VIVO PROTEIN AND PHOSPHOLIPID METHYLATION AFTER IN VIVO ELEVATION OF BRAIN S-ADENOSYL-HOMOCYSTEINE
}

Robert A. Schatz, Timothy E. Wilens and Otto Z. Sellinger

\author{
Laboratory of Neurochemistry \\ Mental Health Research Institute \\ University of Michigan Medical Center \\ Ann Arbor, Michigan 48109
}

Received January 17,1981

SUMMARY

The administration of adenosine together with homocysteine resulted in a dose-related elevation of cerebral S-adenosyl-Lhomocysteine without concomitant perturbation of S-adenosyl-Lmethionine levels. The adenosine + homocysteine treatment also decreased the incorporation of 1 abile and stable methyl groups into brain protęins. Brain $\left[{ }^{3} \mathrm{H}\right]$-phosphatidyl $\mathrm{N}, \mathrm{N}$-dimethylethanolamine and [ $\left.{ }^{\mathrm{H}}\right]$-pho̧sphatidylcholine were also significantly decreased while $\left[{ }^{\mathrm{H}}\right]$-phosphatidyl-N-monomethylethanolamine remained unchanged. The data indicate that elevated brain s-adenosylhomocysteine can markedly and selectively inhibit the in vivo methylation of brain proteins and phospholipids.

\section{INTRODUCTION}

In recent years AdoMet utilizing methylations have been recognized as important in a wide range of biological processes including the chemotactic response (1), vesicle exocytosis (2), the biosynthesis of phospholipids (3), membrane fluidity (4), and ligand-receptor interactions (5). As reported previously, the intraperitoneal (I.P.) co-administration of equimolar Ado and Hcy elevates cerebral, hepatic, and blood levels of AdoHcy without significantly perturbing AdoMet levels $(6,7)$. The elevated

Abbreviations: Ado, adenosine; Hcy, D, L homocysteine; AdoMet, S-adenosyl-L-methionine; AdoHcy, S-adenosyl-L-homocysteine; PME, phosphatidyl-N-monomethylethanolamine; PMME, phosphatidyl-N,Ndimethylethanolamine; PC, phosphatidylcholine; PMT, S-adenosyl-Lmethionine: phosphatidylethanolamine-N-methyltransferase (EC 2.1.1.17); MGI, methyl group incorporation; TCA, trichloroacetic acid. 
tissue AdoHcy levels, in turn, resulted in decreased histamine-Nmethyltransferase (EC 2.1.1.8) and catechol-0-methyltransferase (EC 2.1.1.6) activities as assayed in vitro, as well as in a decrease, in vivo, in the catabolism of brain histamine, which occurs solely by transmethylation to 3 -methylhistamine $(8,9)$. In light of the fact that the methylation of proteins and phospholipids may participate in and/or mediate the regulation of neural activity $(1,5,10,11)$, it became of interest to determine the effects of elevated cerebral AdoHcy levels on these two processes.

\section{MATERIALS and METHODS}

Animals. Adult male Swiss-Webster mice (24-32g) were from Charles River Laboratories (Portage, MI). They were fasted overnight prior to the experimental procedures which were conducted between 8:00 and 11:00 AM.

Drug treatment and tissue collection. Mice were injected intraperitoneally (I.P.) with an equimolar mixture of Ado and Hcy $40 \mathrm{~min}$ prior to sacrifice by immersion (head first) in liquid nitrogen. Brains were rapidly removed, refrozen in liquid nitrogen, and stored at $-80^{\circ} \mathrm{C}$ until time of assay.

Determination of AdoMet and AdoHcy. AdoHcy and AdoMet disulfate di-p-toluenesulfonate were generously donated by Dr. Giorgio Stramentinoli (BioResearch Laboratories, Liscate, Italy). Amberlite CG-50 was from Accurate Chemical (Hicksville, NY) and Dowex 50W-X8 (200-400 mesh), from BioRad (Richmond, CA). AdgMet (methyl-[ $\left.\left.{ }^{14} \mathrm{C}\right]\right)$ (specific activity $57 \mathrm{mCi} / \mathrm{mmol}$ ) and Ado-(8-[ $\left.{ }^{14} \mathrm{C}\right]$ ) (specific activity $54 \mathrm{mCi} / \mathrm{mmol}$ ) were 14 from New England Nuclear (Boston, MA). Radioactive AdoHc $44\left(8-\left[{ }^{14} \mathrm{C}\right]\right)$ was prepared from L-Hcy thiolactone and Ado- $\left(8-\left[{ }^{14} \mathrm{C}\right]\right)$ by high pressure 1 iquid chromatography as previously described (12). AdoMet and AdoHcy levels were determined using a modified isotope-dilution/ion exchange/HPLC method (7).

In vivo protein methylation. $\mathrm{L}$-(methy $\left.]-\left[{ }^{3} \mathrm{H}\right]\right)$-methionine (specific activity, I Ci 侮mol) was from ICN Pharmaceuticals, Inc. (Irvine, $C A$ ) and $L-\left(\left[{ }^{4} \mathrm{C}\right] \mathrm{OOH}\right.$ )-methionine (specific activity, $60.7 \mathrm{mCi} / \mathrm{mmol}$ ) was from Amersham-Segrle (Arlington Heights, IL). For intraventricular (i.vt.) ([ $\left.{ }^{4} \mathrm{C}\right]$ OOH) -methionine and [ $\left.{ }_{\mathrm{H}}\right]-$ methionine injections, the mice were lightly anesthetized with ether, a small piece of scalp removed for ease in identification of the injecticn site and $\left.2 \mathrm{uCi}\left(\mathrm{I}^{14} \mathrm{C}\right] \mathrm{OOH}\right)-$ or $5 \mathrm{uCi}$ ([ ${ }^{3} \mathrm{H}-$ methyl])-methionine was injected into the lateral cerebral ventricle in 10 ul of artificial cerebrospinal fluid (Merlis solution) 2, 30, and $60 \mathrm{~min}$ prior to sacrifice. In all cases, animals were treated with Ado+Hcy or saline/Tween 80 (controls), $40 \mathrm{~min}$ prior to sacrifice (7). Frozen brains were rapidy 
weighed, and homogenized in $8.0 \mathrm{ml}$ of ice-cold $5 \mathrm{mM}$ sodium phosphate buffer ( $\mathrm{pH}$ 6.8), Protein carboxymethylation was determined using the method of Kim (13), modified as follows: Two ml of tissue homogenate was centrifuged $(27,000 \times \mathrm{g}$ for $30 \mathrm{~min})$, after which the pellet was washed three times with $1.0 \mathrm{ml}$ of $5 \mathrm{mM}$ phosphate buffer $(\mathrm{pH} 6.8)$ and once with $1.0 \mathrm{ml}$ ethanol.

To determine the total MGI, the pellet was resuspended in $1.0 \mathrm{ml}$ of $5 \mathrm{mM}$ phosphate buffer and a $0.1 \mathrm{ml}$ aliquot counted in $10 \mathrm{ml}$ of ACS (a tissue solubilizer-scintillation mixture; Amersham-Searle, Arlington Heights, IL). To determine the stable MGI, the washed, resuspended pellet was centrifuged $(27,000 \times \mathrm{g}$ for $20 \mathrm{~min}$ ), and the pellet resuspended in $1.0 \mathrm{ml}$ of $0.2 \mathrm{M}$ sodium phosphate buffer ( $\mathrm{pH}$ 7.4). The mixture was heated in a water bath at $100^{\circ} \mathrm{C}$ for 5 min to hydrolyze methyl esters. The sample was cooled, $5 \mathrm{mg}$ of bovine serum albumin (Miles Biochemicals, Elkhart, IN) added as a carrier, and protein was precipitated with $1.0 \mathrm{ml}$ of $30 \% \mathrm{TCA}$. After centrifuging $(27,000 \times \mathrm{g}$ for 10 min), the resulting precipitate was washed once with $1.0 \mathrm{ml}$ of $158 \mathrm{TCA}$, once with $1.0 \mathrm{ml}$ of ethanol, suspended in $1.0 \mathrm{ml}$ water, and $0.25 \mathrm{ml}$ were counted in $10 \mathrm{ml}$ ACS to obtain values for the stable MGI. The difference between the total (see above) and the stable MGI represents the labile (carboxymethylation) MGI (14). Protein was determined according to Lowry (15).

In vivo phgspholipid methylation. All mice were injected i.vt. with ([ H-methyl])-methionine followed 20 min later with either AdotHcy $(500 \mathrm{mg} / \mathrm{kg}$ of each) or saline/Tween $80(20 \mathrm{ml} / \mathrm{kg})$ I.P. After sacrifice, $60 \mathrm{~min}$ after ([3-methyl])-methionine, brains were processed as above for protein methylation. The first pellet was washed four times with $1.0 \mathrm{ml}$ of $5 \mathrm{mM}$ phosphate buffer ( $\mathrm{pH}$ 6.8). To extract the phospholipids, the washed pellet was suspended in $2.0 \mathrm{ml}$ of chloroform/methanol $(2: 1, v / v)$, the suspension vortexed for $60 \mathrm{sec}$, centrifuged $(27,000 \times \mathrm{g}$ for 30 min) and the supernatant transferred to a screw-capped test tube. This extraction was repeated, and the 2 supernatants combined. The organic phase was washed twice with $2.0 \mathrm{ml}$ of $0.1 \mathrm{M} \mathrm{KCl}$ (in $508 \mathrm{MeOH}$ ), and the aqueous (top) phase aspirated. A $0.1 \mathrm{ml}$ aliquot was counted in $5.0 \mathrm{ml}$ ACS for total phospholipid methylation. The identification of the radioactive phospholipids was by thin-layer chromatography $(16,17)$. The chloroform phase was dried under a stream of nitrogen, the tubes were capped, and stored overnight at $-20^{\circ} \mathrm{C}$. The residue was dissolved in 40 ul of a mixture containing $0.4 \mathrm{mg}$ of each standard: L-a-phosphatidyl-

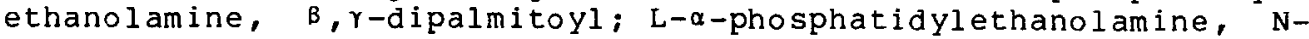

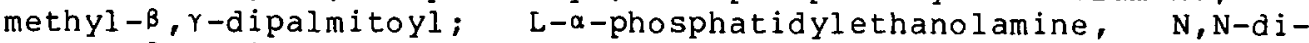

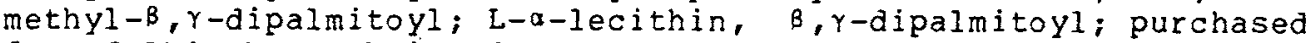
from Calbiochem-Behring Co. (La Jolla, CA), in chloroform/methanol, 2:1, by vol. and 25 ul applied to silica gel 60 plates (without fluorescent indicator) (EM Laboratories, Elmsford, NY). Plates were developed $(16 \mathrm{~cm})$ in chloroform/propionic acid/npropyl alcohol/water $\left(2: 2: 3: 1\right.$, by vol.) $(16,17)$, dried at $100^{\circ} \mathrm{C}$ for $10 \mathrm{~min}$, and sprayed with iodine (18 in ethanol) for detection of phospholipids. After the spots were outlined with pencil, the plates were heated as above to remove iodine, each lane was divided into $1 \mathrm{~cm}$ strips and was scraped into scintillation vials containing $10 \mathrm{ml}$ ACS and the radioactivity determined by the channels ratio method. The identity of the phospholipids was further confirmed in the solvent systems chloroform/methanol/7 M 
ammonia (60:35:5, by vol.) and chloroform/methanol/water (65:25:4, by vol.) by one-dimensional thin-layer chromatography $(16,17)$.

Statistical analysis. Statistical differences between drugtreated groups and corresponding vehicle-treated animals were evaluated by the Student's "t" test (two-tailed). P values less than 0.05 were considered not significant.

\section{RESULTS}

Effect of AdotHcy on Brain AdoMet and AdoHcy Levels, and on the Methylation Index. To determine the effects of Ado+Hcy on AdoMet and AdoHcy levels, mice were injected I.P. with Ado+Hcy $(200 \mathrm{mg} / \mathrm{kg}$ or $500 \mathrm{mg} / \mathrm{kg}$ of each) and killed $40 \mathrm{~min}$ later (Table 1) at which time brain AdoHcy levels are maximally elevated $(6,7)$. Adomet levels remained unchanged, while AdoHcy levels increased in a dose-dependent manner by $500 \%$ and 19208 at 200 $\mathrm{mg} / \mathrm{kg}$ and $500 \mathrm{mg} / \mathrm{kg}$, respectively (Table $1 ; 6,7)$. The methylation index (AdoMet/AdoHcy ratio), used as an index of transmethylation rates in brain tissue (18-20), was conversely, significantly decreased, $-878(200 \mathrm{mg} / \mathrm{kg})$ and $-968(500 \mathrm{mg} / \mathrm{kg})(\mathrm{Table} 1)$.

Effect of Ado+Hcy on Phospholipid Methylation. Figure 1 shows that the co-administration of Ado+Hcy resulted in a significant decrease in the formation of $\left[{ }^{3} \mathrm{H}\right]-\operatorname{PMME}(-608)$ and $\left[{ }^{3} \mathrm{H}\right]-\mathrm{PC}$ $(-758)$, these reactions being catalyzed by the same enzyme, PMT II. The brain levels of $\left[{ }^{3} \mathrm{H}\right]-\mathrm{PME}$, whose formation is catalyzed by a different enzyme, PMT I $(16,17)$, remained unchanged after Ado+Hcy treatment.

Effect of Ado+Hcy on Protein Methylation. Figure 2 shows a time related increase in both the stable (remaining after alkaline hydrolysis) and labile (carboxymethyl esters) MGI into proteins. Ado+Hcy significantly decreased stable MGI by 50 at 2 min and by 538 at $30 \mathrm{~min}$, while at $60 \mathrm{~min}$ there was no longer any difference between the stable MGI in treated vs. control animals. 


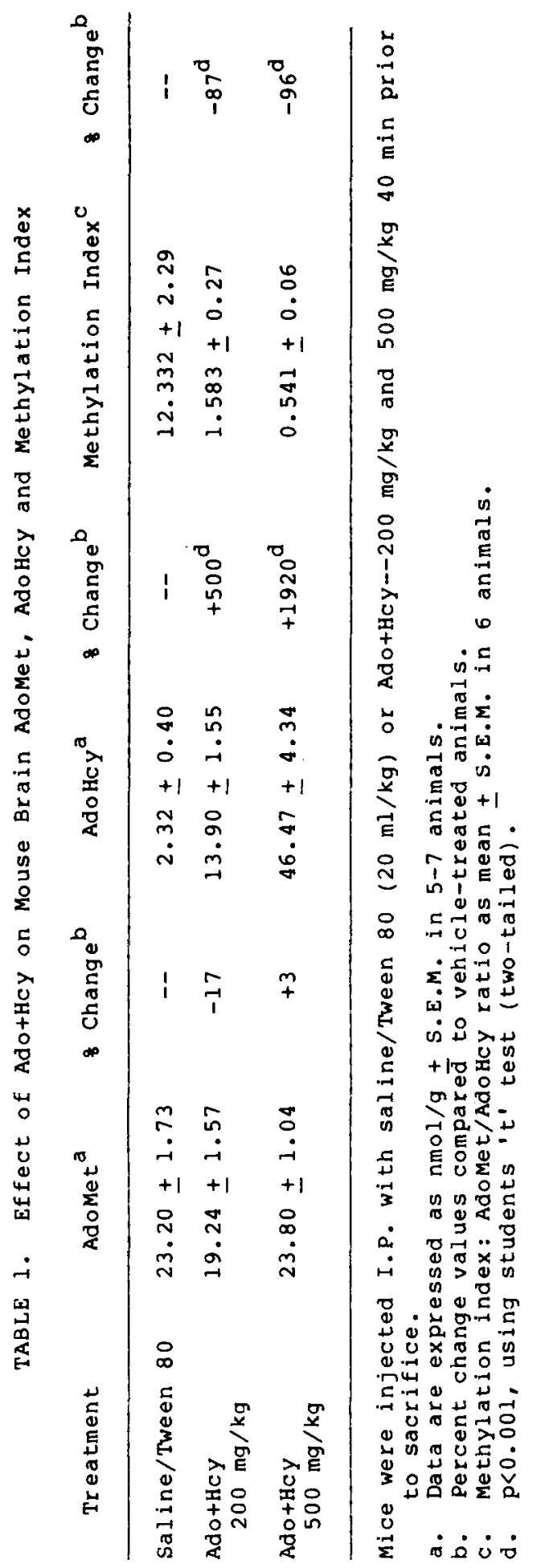




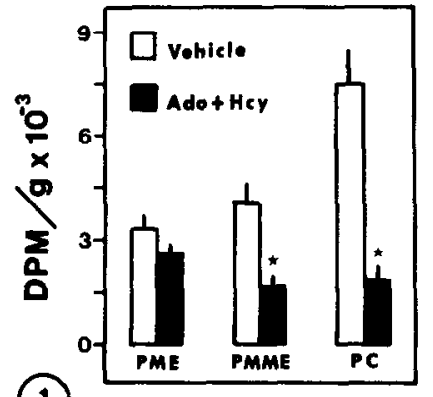

(1)

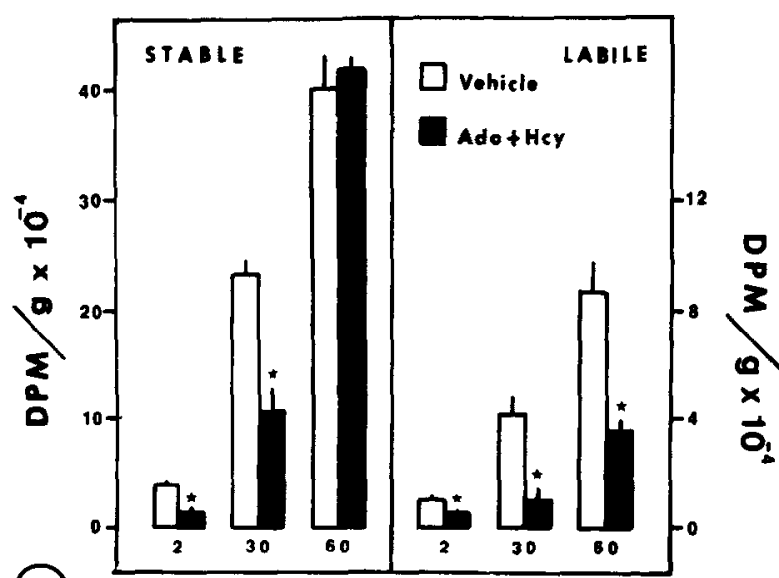

MINUTES

Figure 1. Effect of Ado+Hcy on Phospholipid Methylation in Mouse Brain. $[3 \mathrm{H}]-$ methyl methionine (5 uCi/10 ul) was injected into the lateral cerebral ventricle of mice $60 \mathrm{~min}$ prior to sacrifice. Ado+Hcy $(500 \mathrm{mg} / \mathrm{kg}$ of each) or saline/Tween 80 (20 ml/kg) was injected intraperitoneally $\$ 0 \mathrm{~min}$ before death. Results are expressed in $\mathrm{dpm} / \mathrm{g} \times 10^{-3}+\mathrm{S} . \mathrm{E} . \mathrm{M}$. in 5-7 mice. . Denotes a significant difference compared to corresponding vehicle-treated controls at the 0.05 level using the student ' $t$ ' test.

Figure 2. 3 Effect of Ado+Hcy on Protein Methylation in Mouse Brain. $\left[{ }^{3} \mathrm{H}\right]-$ methyl methionine (5 uCi/10 ul) was injected intraventricularly 2, 30 and $60 \mathrm{~min}$ prior to sacrifice. Ado+Hcy 1500 $\mathrm{mg} / \mathrm{kg}$ of each) or saline/Tween $80(20 \mathrm{ml} / \mathrm{kg})$ was injected intraperitoneally $40 \mathrm{~min}$ prior to death. Methyl group incorporation was determined as described in "Materials and Methods". Results are expressed in $\mathrm{dpm} / \mathrm{g} \times 10^{-4} \pm \mathrm{S} . \mathrm{E} . \mathrm{M}$. in 5-7 mice. For statistical analysis, see Figure 1 .

Furthermore, the administration of Ado+Hcy significantly decreased labile MGI (protein carboxymethylation), by 428,748 , and 608 at 2,30 , and $60 \mathrm{~min}$, respectively.

\section{DISCUSSION}

We have previously shown that the co-administration of equimolar AdotHcy results in elevated AdoHcy levels in mouse brain $(6,7)$. We established that the methylation index (AdoMet) AdoHcy) was reduced after Ado+Hcy (Table 1) supporting the idea that this ratio is a reflection of brain methylation activity $(18,19)$, as suggested by others for several of the methyltransferase enzymes (20), including PMT I and II (21). 
It is well established that PC can be synthesized by two distinct pathways in brain: 1) the conversion of free choline to CDP-choline and a phosphobase transfer to form 1,2-diacylglycerate (22), or 2) the stepwise methylation of phosphatidylethanolamine to PC using two AdoMet dependent methyltransferases $(3,16,17)$.

As shown in Figure 1, there appears to be little inhibition by Ado+Hcy of $\left[{ }^{3} \mathrm{H}\right]-\mathrm{PME}$ formation perhaps because by $60 \mathrm{~min}$ labelling of PME may have begun to decay or because the newly formed AdoHcy fails to interact with and, hence inhibit PMT I. since no inhibition of [ $\left.{ }^{3} \mathrm{H}\right]-\mathrm{PME}$ formation was noted after a 10 min [ ${ }^{3} \mathrm{H}$-methyl]-methionine pulse $(30 \mathrm{~min}$ prior to Ado+Hcy) (data not shown), the former option appears unlikely although further time studies need to be carried out to totally rule out this possibility. A likelier explanation is that since PMT $I$ is an intrasynaptosomal enzyme $(17,23)$, it is not accessible to the intact AdoHcy molecule which may be located for the most part extrasynaptosomally. This supposition is further borne out by studies which show the impermeable nature of membranes to AdoHcy $(7,24-26)$. Further, the addition of AdoHcy did not alter the viscosity of erythrocyte membranes (4) or, by inference, PME levels. Kinetic studies with PMT I indicate that invitro decreased PMT I activity does, in fact, occur simultaneously with a decrease in the methylation index (21). The inhibition by Ado+HCy of $\left[{ }^{3} \mathrm{H}\right]-\mathrm{PMME}$ and $\left[{ }^{3} \mathrm{H}\right]-\mathrm{PC}$ formation reflects inhibition of PMT II. PMT II is thought to be located on the outside of the synaptosomal membrane (23) and hence more readily accessible to external AdoHcy. PMT II also has a high affinity for AdoMet and an even higher affinity for AdoHcy $(21,27)$. The present findings support the results of Chiang and Cantoni $(28,29)$ who found that 
elevated hepatic AdoHcy levels inhibited hepatic [ $\left.{ }^{3} \mathrm{H}\right]-\mathrm{PC}$ formation. Yet, since our procedure for administration of Ado+Hcy (as opposed to deazaadenosine administration $(28,29)$ ), insured increases in AdoHcy levels without perturbations in AdoMet levels and in the absence of any deaza-adenosylhomocysteine, it is possible to relate PMT II inhibition directly to the elevated AdoHcy levels generated by the Ado+Hcy administration. To date there are three different enzymes known which are responsible for the N-methylation of either lysyl, arginyl or histidyl residues (referred to in this paper as stable MGI), or the 0-methylation of carboxyl groups (referred to as labile MGI) $(10,30)$, the latter reaction being catalyzed by protein methylase II (31). As shown (Figure 2), treatment with Ado+Hcy markedly decreased the labile MGI at all times tested and the stable MGI at the two earlier time points. Of interest is the positive correlation between the observed in vivo inhibition and in vitro kinetic studies. Assuming a 708 volume of distribution (32) at the higher dose of AdotHcy $(500 \mathrm{mg} / \mathrm{kg})$, this should result in intracellular AdoHcy concentrations of $0.75 \mathrm{uM}$, which is well within the range of $\mathrm{Ki}$ values $\left(6.5 \times 10^{-9} \mathrm{M}\right.$ to $\left.6 \times 10^{-6} \mathrm{M}\right)$ determined for protein methyltransferases I-III $(10,20,33)$. The in vivo inhibition of labile MGI (42-608) (Figure 2) is within the expected values. The decreased methylation ratio, as mentioned, infers that the inhibition of stable or labile MGI is directly caused by the high intracellular AdoHcy levels. We do not find the failure of stable MGI to be reduced at $60 \mathrm{~min}$ as surprising, for all the available protein N-methylation sites may have become irreversibly occupied by $30 \mathrm{~min}$. Another possibility is that the $\left(\left[{ }^{3} \mathrm{H}-\right.\right.$ methyl $\left.]\right)$-methionine, administered $20 \mathrm{~min}$ before Ado+Hcy, may have methylated all sites before AdoHcy levels had 
increased sufficiently to inhibit this process. That these differences in stable and Iabile MGI are due to incorporation of only the methyl group of methionine, and not of the intact methionine molecule, is supported by preliminary experiments in which there were no differences in incorporation of $\left(\left[{ }^{14} \mathrm{C}\right] \mathrm{OOH}\right)-$ methionine into cerebral proteins comparing control and Ado+Hcytreated mice (data not shown).

With the recent evidence of increased protein 0-methylation simultaneous with increased neurosecretion in the pituitary and parotid glands $(34,35)$ and in the adrenal medulla (2), the ability to slow the rate of this methylation by raising endogenous AdoHcy levels may be of importance for modulation of neural activity in general.

In addition, the demonstration of a role of the stepwise methylation of the membrane phospholipids in membrane fluidity (4) and in ligand-receptor interactions (5) again reflects the importance of controlling endogenous AdoHcy levels.

The notion that AdoHcy is a neural modulator is further expanded by preliminary evidence from several laboratories including ours (unpublished observations) which shows that AdoHcy possesses sedative (36) as well as anticonvulsant (37) properties.

\section{ACKNOWLEDGMENTS}

This work was supported by a grant from the U.S. Public Health Service, NINCDS 06294 (0.Z.S.) and by the University of Michigan student work-study program (T.E.W.).

\section{REFERENCES}

1. Borchardt, R. T. (1980) J. Med. Chem. 23, 347-357.

2. Diliberto, E. J. Jr., Viveros, O. H., and Axelrod, J. (1976) Proc. Natl. Acad. Sci. 73, 4050-4054.

3. Bremer, J., and Greenberg, D. M. (1961) Biochim. Biophys. Acta. 46, 205-216.

4. Hirata, F., and Axelrod, J. (1978) Nature 275, 219-220. 
5. Hirata, F., Strittmatter, W. J., and Axelrod, J.

Proc. Natl. Acad. Sci. 76, 368-372.

6. Schatz, R. A., Wilens, T. E., and Sellinger, 0. Z.

Trans. Am. Soc. Neurochem. 11, 244.

7. Schatz, R. A., Wilens, T. E., and Sellinger, 0. Z. $\mathrm{J}$. Neurochem. In press.

8. Schwartz, J. -C., Pollard, H., Bischoff, S., Rehault, M. C., and Verdiere, M. (1971) Eur. J. Pharmacol. 16, 326-335.

9. Schwartz, J. -C., Barbin, G., Garbarg, M., Pollard, H., Rose, C., and Verdiere, M. (1976) Adv. Biochem. Psychopharm. 15, 111-126.

10. Kim. S., Galletti, P., and Paik, W. K. (1979) In Biochemical and Pharmacological Roles of Adenosylmethionine and the Central Nervous System (Zappia, V., Usdin, E., and Salvatore, F., eds.) pp.37-50.

11. Gagnon, C., and Heisler, S. (1979) Life Sci. 25, 993-1000.

12. Schatz, R. A., Vunnam, C. R., and Sellinger, O. Z. (1977) Life Sci. 20, 375-384.

13. Kim, S., Galletti, P., and Paik, W. K. (1980) J. Biol. Chem. 255, 338-341.

14. Kim. S. (1977) In The Biochemistry of Adenosylmethionine (Salvatore, F., Borek, E., Zappia, V., Williams-Ashman, H. G., and Schlenk, F., eds.) pp. 415-434, Columbia University Press, New York.

15. Lowry, O. H., Rosebrough, N. J., Farr, A. L., and Randall, R. J. (1955) J. Biol. Chem. 193, 265-275.

16. Hirata, F., Viveros, O. H., Diliberto, E. J., and Axelrod, J. (1978) Proc. Natl. Acad. Sci. 75, 1718-1721.

17. Crews, F. T., Hirata, F., and Axelrod, J. (1980) J. Neurochem. 34, 1491-1498.

18. Baudry, M., Chast, F., and Schwartz, J. -C. J. Neurochem. 20, 13-21.

19. Schatz, R. A., Vunnam, C. R., and sellinger, O. Z. Neurochem. Res. 2, 27-38.

20. Cantoni, G. L., Richards, H. H., and Chiang, P. K. (1979) In Transmethylation (Usdin, E., Borchardt, R. T., and Creveling, C. R.' eds.) pp. 155-164, Elsevier/NorthHolland, New York.

21. Hoffman, D. R., Uthus, E. O., and Cornatzer, W. E. (1980) Lipids $15,439-446$.

22. Kennedy, E. P., and Weiss, S. B. (1956) J. Biol. Chem. 222, 193-197.

23. Crews, F. T., Hirata, F., and Axelrod, J. (1980) Neurochem. Res. 5, 983-991.

24. Duerre, J. A., Miller, C. H., and Reams, G. G. C. (1969) J. Biol. Chem. 244, 107-111.

25. Walker, R. D., and Duerre, J. A. (1975) Can. J. Biochem. $53,312-319$.

26. Knudsen, R. C., and Yall, O. (1972) J. Bacteriol. 112, 569-575.

27. Hoffman, D. R., and Cornatzer, W. E. (1978) Fed. Proc. 37, 1833.

28. Chiang, P. K., and Cantoni, G. L. (1979) Biochem. Pharmaco1. 28, 1897-1902.

29. Chiang, P. K., and Cantoni, G. L. (1980) Biochem. Biophys. Res. Comm. 94, 174-181.

30. Paik, W. K., and Kim, S. (1980) Protein Methylation, Biochemistry: A series of monographs $1,1-209$, (Meister, $\bar{A}$, ed.) John Wiley and Sons, New York. 
31. Kim, S. (1973) Arch. Biochem. Biophys, 157, 476-484.

32. Cizek, L. J. (1954) Am. J. Physiol. 179, 104-110.

33. Casselas, P., and Jeanteur, P. (1978) Biochim. Biophys. Acta. 519, 255-268.

34. Diliberto, E. J. Jr., and Axelrod, J. (1974) Proc. Natl. Acad. Sci. 71, 1701-1704.

35. Strittmatter, W. J., Gagnon, C., and Axelrod, J. (1978) J. Pharmacol. Exp. Ther. 207, 419-424.

36. Fonlupt, P., Roche, M., Cronenberger, L., and Pacheco, H. (1980) Can. J. Physiol. Pharmacol. 58, 160-166.

37. Fonlupt, P., Roche, M., Andre, A. C., Cronenberger, L., and Pacheco, H. (1980) Can. J. Physiol. Pharmacol. 58, 493-498. 